\title{
Farmers Markets and Fairs as Venues for Doing Math in Rural Settings
}

\author{
Jan Mokros ${ }^{1}$, Jennifer Atkinson ${ }^{1}$ \\ ${ }^{1}$ Maine Mathematics and Science Alliance, Augusta, Maine \\ Keywords: mathematics \\ Publication Date: November 27, 2018 \\ DOI: https://doi.org/10.15695/jstem/v1i1.23
}

\begin{abstract}
This paper describes innovative ways of bringing mathematical learning into community venues in rural settings. We selected highly engaging mathematical activities, adapted them for middle school youth and their families, and brought them to the "locavore" contexts of Farmers Markets and community agricultural fairs. "STEM Guides"-community people hired to connect youth with local STEM resources - set up math-oriented booths at local Farmers Markets and fairs. They enlisted visitors in weighing produce, comparing weights of typical fruits/vegetables to record-weighing produce, and composing community-supported agriculture (CSA) baskets with specified ratios of different types of produce. Pilot findings from four trials with 91 participants are reported. Specifically, we examine: 1) features of participant engagement; and 2) ways of matching venues with meaningful place-based mathematics, in this case, measurement and mental mathematics. This work demonstrates that it is possible to start with a local venue, identify key mathematical concepts that are woven into this venue, and incorporate mathematics that appeals to a variety of participants. We discuss the idea of important and familiar mathematics reflecting community activities and settings; and the benefits of making math more of a place-based, community-oriented enterprise.
\end{abstract}

\section{INTRODUCTION}

The work described in this paper, Farmers Market Math, took place in Maine, the most rural state in the U.S. It was part of a larger project, the STEM Guides Project, which brings science, technology, engineering and math [STEM] to 10- to 18-year-old youth and their families in out-of-school settings.

Rural students are, by most definitions, geographically isolated and live in communities consisting of fewer than 2,500 people (Coladarci, 2007). While rural students achieve high school graduation at higher rates than their urban peers, their attainment lags behind with respect to higher education (Table 1).

Rural youth are also less than half as likely as urban youth to attend STEM events or programs in their free time. For example, recent research shows that $14 \%$ of middle school students in rural areas, versus $31 \%$ in urban areas, participated in out-of- school STEM programs (Vital Signs, 2012). The authors of the report conclude, "At a time when we should be leveling the playing field for rural children, low participation in out-of-school STEM programs is actually exacerbating the disparities." (Vital Signs, 2012, p. 2). But might there be an existing, though unrecognized, genre of out-of-school STEM programs that can be adapted to reach many rural youth and their families?

The aim of the STEM Guides Project is to connect with youth where they live, using a unique system of place-based STEM Guides-people skilled in education and/or youth development who live in rural areas (STEM Hubs) which vary in size from entire counties to single regional school districts. STEM Guides are hired to serve as connectors, resource people, and facilitators of vetted and high-quality STEM programs and activities for the youth and families in their STEM Hub. Our part-time, paid STEM Guides find

Table 1. Comparing educational milestones between rural and urban populations

\begin{tabular}{lcc}
\hline Educational Attainment & Rural & Urban \\
\hline $\begin{array}{l}\text { Average Freshman Graduation } \\
\text { Rate (public high school) }\end{array}$ & $79.90 \%$ & $67.70 \%$ \\
$\begin{array}{l}\text { Attend IHE following fall (\% high } \\
\text { school graduates) }\end{array}$ & 59 & 62 \\
$\begin{array}{l}\text { Hold bachelors' degree or higher } \\
\text { (\% of population) }\end{array}$ & 19.5 & 29 \\
\hline
\end{tabular}

$\overline{\text { (National Center for Education Statistics, 2013; National Student Re- }}$ search Clearinghouse, 2016; US Census Bureau, 2016) 
the resources in their communities or online, ensure that youth and their families are informed about and able to access these resources, and encourage youth to get involved. (Maine Mathematics and Science Alliance, 2018)

In the first years of the project, as the STEM Guides began working in their rural hubs, we discovered a serious gap in programming in a crucial area of STEM: mathematics. This paper describes one of the ways we worked to address this gap. We made mathematics more visible, connected and exciting by bringing it to some of Maine's Farmers Markets and agricultural fairs and engaging youth and their families in math at these popular community venues. Because bringing more educational opportunities to families is an explicit goal of the Maine Association of Agricultural Fairs (2018), these venues seemed like a good fit for our work. The rising popularity of Farmers Markets and agricultural fairs in rural Maine provides a potentially important context for engaging youth and their families in genuine mathematics.

\section{BACKGROUND: TWO FRAMEWORKS}

1) Place-Based Math. Place-based math education (PBME) has received attention recently as a strategy for engaging students in relevant and authentic mathematics (Howley et al., 2005; Howley et al., 2011; Showalter, 2013). The assumption is that PBME 'increases students' awareness of what is worth preserving in their local community and environment while at the same time equipping them with a sense of agency that they can make a difference in realizing this preservation" (Showalter, 2013, p. 3.). While there is some research on the effectiveness of PBME, much of it has been done in the classroom rather than outside of school. Much of this work focuses on cultural contexts, such as Latino cultural and family contexts (Civil et al., 2003; Civil et al., 2005; Civil, 2007) or on social justice and inequality contexts that typify diverse urban areas (Gutstein, 2006). In many cases, the focus has been on addressing social problems that affect young people by using mathematics as a tool. Less attention has been given to surfacing the mathematics that is salient in rural places.

In school mathematics, there is a significant tension between engaging in rigorous mathematics that is aligned with state and national standards, on the one hand, and engaging in authentic, place-based mathematics that is familiar and engaging to youth, on the other (Kannapel et al., 2000). Tieken (2014) discusses the significance of this tension in rural areas, where schools are torn between complying with subject-based standards and engaging students in themes and topics that are inherent in their own places. For example, she notes the irrelevance of school worksheets that incorporate problems relating to riding on an escalator, when many rural children have never seen an escalator.

This tension is minimized in the out-of-school arena, where there is no requirement to "teach to the standards." Outside of school, youth are free to engage in place-based mathematics that is related to salient community issues and contexts. Given the omnipresence of math in everyday life, one might expect a plethora of place-based mathematical activities in afterschool and summer programs, where children and educators are able to take field trips, explore the outdoors, and engage in projects that spill over the bounds of conventional class periods.

However, we have found that mathematical programs and activities are not well represented in the out-of-school arena, especially when compared to the abundance and variety of out-of-school science and engineering activities. In a well-known online database of such activities, "howtosmile" (2018), about ten times more science activities are listed than math activities. There are still hundreds of online math activities (mostly puzzles and games) for children and families to choose from, but very few are place-based. In Maine, we have constructed a statewide STEM Resource Bank (2018) consisting of STEM programs and events that happen outside of school. Of the more than one hundred listings, there are only four offerings in Maine, two competitions and two summer camps, that focus specifically on mathematics.

Perhaps mathematics is not being addressed in relevant and authentic ways in out-of-school settings because it is considered too academic, too boring, or not a good fit for out-of-school programs. Traditional mathematics is widely incorporated into structured afterschool enrichment or remediation programs. We find a great deal of attention being paid to mathematics in afterschool programs like 21st Century Learning Centers, but the mathematics provided is basically in the service of school math, as required by law. It is largely worksheet-based or homework-based (U.S. DOE, 2015). The second type of math that is sometimes done in out-ofschool arenas is competitive math. While competitions such as the American Mathematical Competitions (Mathematical Association of America, 2018), Math Olympiads (2018), or MATHCOUNTS (2018) typically are classroom-based, some preparation for these competitions happens outside of school. To an overwhelming extent, what's available in math outside of school is either competition-based or school-math focused (or both).

Nationally, there are a couple of shining examples of math clubs or other math programs that are intended to engage a broad and diverse group of youth in math that is both fun and challenging. The Math Circles program, for example, is "mathematically rigorous, but the atmosphere is friendly and relaxed. We want our students to feel free to express their ideas, to suggest their own approaches, and to make mistakes. We work in a spirit of friendship, cooperation, and enjoyment of one another." (National Association of Math Circles, 2018). Interestingly, Math Circles recently have been adapted to serve the needs of particular populations. 
The program in the Navajo Nation incorporates elements of the Navajo culture, making it more place-based (Gilon, 2017). The National Math Club program (2018) is also non-competitive and engages middle school youth in mathematics that is meant for enrichment. This program can be done online, which makes it easier for rural youth to become involved. Increasingly, genuine mathematics is also being incorporated into science center exhibits and programs (Design Zone, 2018; MathMoves, 2018; and MathAlive Exhibit, 2018). However, exhibits like these are not available for those who live in less-populated rural areas, where there are few science centers, and the ones that exist are very small.

Note that none of the national out-of-school math programs identified above feature place-based mathematics. National clubs and competitions are relatively uniform, even those, like Math Circles, that can be adapted to target specific populations. Any variation is likely attributable to the leaders and to the ways that youth interact with structured materials. There is, however, one important exception: "Math in the Garden" is necessarily connected with local farms and gardens (University of California and the National Gardening Association, 2006). The math activities in this program for elementary-aged children emphasize counting, proportional reasoning, measurement, and algebraic thinking. For example, several activities involve weighing and comparing different pieces of produce. The math is approachable through a wide range of strategies other than pencil and paper calculation, with an emphasis on using the produce itself as a manipulative or hands-on "prop." These short, highly visible and engaging problems promote collaborative work and can be solved in many different ways. The activities focus on gardening as it occurs in students' own backyards.

2) Math, Families, and Everyday Life. Just as there is little research about place-based programs outside of school that feature engaging and genuine mathematics, there is not much research about how mathematics takes place as part of families' everyday lives. (Tiedemann and Brandt, 2010; Van Voorhis et al., 2013). However, an important exception is research on Latino families' involvement and support of mathematics learning both at home and at school. Marta Civil and her colleagues have done extensive investigations of ways in which school-based mathematics can build upon the mathematics that is inherent in community and family activities (Civil, 2010). Civil concludes that family interests, as well as family values about teaching and learning and contexts where it takes place, are critical starting places for involving families in mathematics.

Other research focuses on young children, ranging from preschool through about age 8 . At these ages, parents build on familiar strategies for reading aloud to their children. In fact, the most common mathematical intervention suggested to parents is to incorporate more mathematical books into their reading aloud routines. There are hundreds of counting books for young children, and an increasing number of mathematically-based storybooks for children in the early elementary grades. In fact, there are several bibliographies for parents and teachers that contain annotated listings of math books, mostly for reading aloud (Burns and Sheffield, 2004; Gailey, 1993).

While reading books aloud promotes families' engagement in mathematics, it is curious that there is not more focus on the abundant ways in which "real" family life can incorporate mathematics in a visible, engaging, and explicit way. Parents, like all adults, regularly engage in mathematics as part of everyday life at home and in the community. However, they are often at a loss when it comes to recognizing or articulating the mathematics they are doing. Perhaps the difficulty lies in the narrow definition of "mathematics" as a domain: Most people recognize only a small sliver of what mathematical thinking entails, largely what they remember from their own experiences with school math. Large areas of mathematics, then, are not labeled as math by either parents or their children. For example, mathematics involves estimation, comparing weights or distances, and figuring out approximate costs. However, until one needs pencil and paper or a calculator to determine an exact answer, few people consider these tasks to involve true "math." Bishop (1988) has discussed the difference between math with a small " $m$ " and Math with a capital "M." He believes that using common sense strategies to deal with everyday math problems is devalued compared to the loftier, equation-based "Mathematics" that signifies high-level abstract thinking.

Families often have opportunities to do mathematics together as part of doing craft activities, playing games, shopping at the grocery story, traveling together, engaging in or watching sports, and figuring out how to fairly share treats and other valued resources (Kliman, 2006; Mokros, 1996). And rarely is this unrecognized form of mathematics seen as burdensome: Most parents know that children care intensely about how to divide a pan of brownies fairly, and that it matters to children how much longer they can stay up before going to bed. But highlighting the math in these everyday opportunities and learning how to "talk math" with their children, is something that most adults don't think about.

\section{THE DESIGN: MATHEMATICS AND LOCAL FOOD}

A key premise of our overarching STEM Guides Project is that youth should be involved in all four areas of STEM outside of school - including mathematics - and that this involvement should be relevant to their own lives and to what is happening in their communities. During afterschool hours and especially during the summer, there are not enough opportunities for children to learn mathematics. But other than 
sending their children to expensive summer camps focused on mathematical aspects of STEM, where might math learning occur in meaningful contexts for rural youth?

As we struggled with this question, we were aware from our own experiences that Farmers Markets, community-supported agriculture (CSA), and agricultural/community fairs are omnipresent in Maine, as they are in many areas of rural America. About $5 \%$ of Maine residents $(60,000$ people) attend the Maine Organic Food Grower's Association's Common Ground Fair each year, and over 850,000 attend the 26 official agricultural fairs annually in Maine (Maine Association of Agricultural Fairs, 2018), out of a state population less than 1.3 million. Approximately 20,000 attend the local Damariscotta Pumpkinfest - more than double the number of people who live in the region (Kamila, 2012). There are over 180 farms in the state that sponsor CSAs, and well over 100 Farmers Markets that have their own websites (MOFGA, 2018). Local agriculture is a major and growing occupation in Maine's rural communities. We raised the question: To what extent could Farmers Markets and local agricultural fairs provide visible place-based venues for doing relevant mathematics in rural settings? Of course, these venues are not unique to rural settings, but they are perhaps more salient to rural residents. Community fairs in rural areas are described by Maureen Porter as a "context for youth experiences of learning and belonging" (1995, p. 139).

We explored the feasibility of incorporating math into local agricultural events and Farmers Markets to gauge if they might be suitable, out-of-school venues for making mathematics more visible, connected and exciting for local youth. We called the organizers of these markets and asked them about the numbers and types of customers, with an emphasis on determining the mix of ages and types of people who attend. We found that some markets were geared more to tourists, while we were more interested in those that primarily served the local population and that families with children attended regularly. As we talked with the farmers who organized the markets, we found out more about their work and began making connections with them around mathematics. For example, some farmers distributed CSA shares at the market, and the composition of each week's share differed depending on what was growing. The type as well as the ratio of crops in the CSA baskets differed from week to week and was usually not known in advance.

As we learned more about these markets and events, we searched for mathematical activities or programs that STEM Guides could use and that were closely aligned with the activities of agricultural venues. A premise of our overarching STEM Guides Project is that inexpensive existing resources are abundant and can be tweaked to meet the needs of the rural youth we serve. We found several excellent mathematical problems from three programs: "Math in the Garden" (2006); "Family Math" (1998); and "Investigations in Num- ber, Data and Space" (2015). As we explored these resources, we concluded that the most important mathematics in Farmers Markets involved weighing, estimating, comparing, and using mental math. These are essential mathematical topics (CCSS-M) in upper elementary and middle school grades. In the case of measurement, schools are stretched too thin to provide enough opportunities to practice weighing and measuring real objects. Measurement of any kind remains an opaque abstraction for many children. (NCTM, 2003).

We adapted selected activities from the programs noted above for interactive "fruit and vegetable math" booths in Farmers Markets and community festivals. Initially, our STEM Guides were apprehensive about facilitating the mathematics involved in comparing the weights of typical versus record-weighing vegetables. They also lacked confidence in a task that involved composing a CSA basket with different ratios of vegetables. As a result, we decided to engage them in doing the activities for themselves and examining the underlying mathematics.

We focused on a task where they estimated how many "regular" strawberries would collectively weigh the same as the world-record weighing strawberry (8.1 ounces). At one of our quarterly project retreats, we gave the Guides scales, bowls of strawberries, and plastic bags. A couple of Guides recalled (correctly) that the formal mathematics of this task involves dividing with fractions, and they were not sure they remembered the process. Did one divide 8.1 into 0.5, or 0.5 into 8.1 , and how exactly did one move the decimals? The Guides attempted to retrieve memories of school math to do this division. Staff suggested forgetting about schoollearned strategies. Instead, we encouraged mental math strategies. One of these was to weigh a few strawberries and see how that information helped to build up to a reasonable answer (using either addition or multiplication). The second, related strategy we suggested was to think about how many strawberries it would take to weigh 1 ounce, then build up to roughly 8 ounces from that point. Given that it was usually the case that 2 to 3 strawberries (combined) weighed an ounce, it was easy for people to see that $2 \times 8$ or $3 \times 8$ gave a range of between 16 and 24 strawberries that would collectively weigh "about" 8.1 ounces. Having this range was reassuring as a starting point.

When it came to computations, it was sometimes difficult for the STEM Guides to give up the idea of a single "right answer." Most adults have the misconception that mathematics involves single clear-cut answers. However, it was important to convey that just because there is not a single right answer, one does not accept any answer as reasonable. Just as there is not a single right answer in this instance, there is clearly a range of answers that is reasonable; and determining this range of reasonable possibilities is a key piece of mathematical reasoning. We focused on obtaining reasonable results as we engaged with this problem. Following this 
mathematical experience, the STEM Guides reported that they had gained confidence in their ability to facilitate the activity. They were relieved to learn that they could do the math, and they could do the math just as well when they did not use school-learned algorithms.

The booths, staffed by the newly trained STEM Guides (as well as local teens who served as their assistants), were stocked with produce that is used in two or three key math activities. Each booth also included tools for sorting, weighing, measuring, and keeping track. Depending on the availability of produce over the summer, a different featured activity was introduced to all comers, with an emphasis on attracting young adolescents (10- to 14-year-olds). The booths invited people to become engaged. Large posters of record-weight fruits and vegetables were prominent, including one poster with a "fake" record vegetable (Figure 1). People become curious about these records, and about which poster was fake, and were drawn in to explore what was happening.

An example of an activity involved the strawberry task described above. The activity the STEM Guide posed was simple. Participants were encouraged to hold a strawberry and feel its weight, then weigh it on a digital scale (which could be adjusted to use grams or ounces). In most cases, local strawberries weighed between 0.25 and 0.5 ounces. Then, they asked visitors to the booth to make a prediction: "About how many strawberries like these would it take to tie the record-weighing 8.1-ounce strawberry?" Discussion with whomever was around was encouraged. People sometimes noted that not all strawberries were created equal, which made it harder to estimate. This worked to our advantage, as the goal was to make mathematically meaningful approximations. During this time, pencils and post-it notes were available, but the STEM Guides encouraged people to use mental mathematics, which is an important skill that

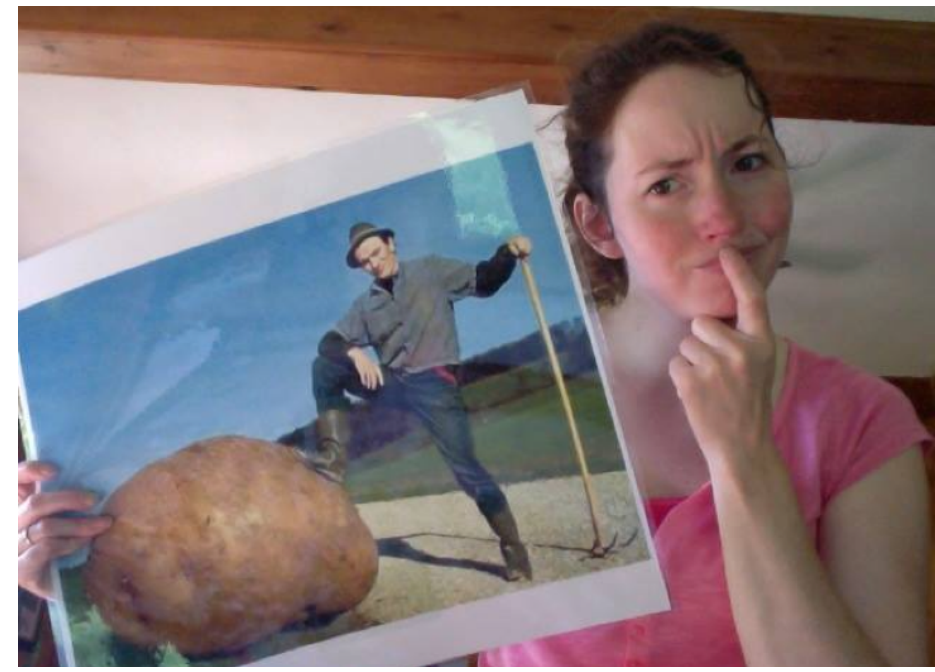

Figure 1. Real or not? STEM Guide, Alyson Saunders, used this poster of an enormous potato to attract youth to her "locavore math" activities at the Dover Cove Farmers Market in western, Maine. prepares middle school youth for algebra (Goldenberg and Sheingold, 2007). Once they had made a prediction, visitors were asked to use a plastic bag and pick out as many strawberries as they thought would tie the record, and then weigh them. The task was iterative in the sense that weighing was encouraged whenever a participant wanted to do it. This gave people an increasingly confident sense of how close they were getting to an appropriate answer.

Our expectations about what type of produce would be available on a given day were frequently wrong. However, when STEM Guides had to make substitutions, online resources such as the Guinness Book of Records (2015) provided immediate information and photos of all types of record-weighing fruits and vegetables. At one market, there were not enough strawberries for sale, but there was an abundance of turnips. But the Guide did not have a scale that would handle the weight of a bunch of turnips that would tie the record-holding turnip (33 pounds). She solicited the help of one of the farmers at the market, who loaned her his scale. In other cases, visitors had to extrapolate rather than weigh items directly. This limitation encouraged another kind of mathematical thinking, namely, scaling up.

\section{FINDINGS}

Results of one summer's work in four rural Maine towns show that "mathematical niches" can be embedded in popular community venues like fairs and Farmers Markets. In this pilot work, we examined: 1) the ways in which participants of various ages engaged with the mathematics; and 2) the ways in which venues can incorporate meaningful mathematics that is tailored to reflect community needs, values, and interests.

1) Participant Engagement. We did not formally collect participant data in this pilot work. The findings we describe are derived from records of and discussions with the STEM Guides. The Guides were busy implementing the activities while at the same time they were documenting who attended and what they were doing. Guides tried out our math booths seven times in three different communities: six times at Farmers Markets and once at a community fair called "Family Fun Day." All told, 91 people participated, with 52 participating in Farmers Market venues and 39 attending the booth at Family Fun Day. About two thirds of the visitors to the booths were children, and one third were adults.

The Guides found that "dwell time" at the booths ranged from a couple of minutes to a half hour, with a median of approximately ten minutes. Families and pairs of youth often spent longer at the booths than did single individuals. Interestingly, Guides reported that younger children (those roughly under 10 years old) were engaged for longer periods of time and showed more persistence than did older chil- 
Table 2. Farmer's Market Math Activity, Participation by Event Type

\begin{tabular}{lcc}
\hline Event Type & \# Events & $\begin{array}{c}\text { \# Participants (Adults and } \\
\text { Youth) }\end{array}$ \\
\hline Farmer's Market & 6 & 52 \\
"Family Fun Day" Fair & 1 & 39 \\
Total & 7 & 91 \\
\hline
\end{tabular}

dren. Younger children were particularly interested in the task of weighing, using both digital scales and pan balances, and they spent considerable time weighing many pieces of produce. (Fig. 2). They were interested in units of measure, experimenting with weighing the items in both grams and in ounces.

It is common in science centers for math exhibits to attract an audience that is younger than the intended age range (Mokros, 2006), and we found a similar phenomenon. Adapting to the expanded age range was relatively easy. Having simple scales and other materials for weighing and measuring enabled young children to engage in age-appropriate math, while their older siblings or friends (our target audience) worked on the mental math problems that we had posed.

Older youth were more likely to complete the task, usually using mental math, and then move on. However, in cases where we enlisted teenagers to demonstrate or facilitate the activity, older youth visiting the booths engaged for longer periods of time. These youth then attracted their peers and engaged in conversations with them (though it is not clear the extent to which these conversations were mathematical). Teens who served as facilitators also had opportunities to improve their own math skills as they worked through the problems with others.

While children and youth were engaged in the activities, parents and other adults sometimes engaged with the math (more typically when they accompanied younger children), and more often engaged with the STEM Guides. This was an opportunity for the Guides to talk more about everyday math and about math resources that could help meet a particular family's needs.

\section{2) Tailoring Venues to Reflect Community Values and} Celebrations. Not all venues are created equal, and it is important to match the needs and interests of those who are likely to participate with the mathematics that can be done. We found that in one of our STEM Hubs, Farmers Markets were attended by people of many ages. Parents and grandparents brought their children/grandchildren and were eager to do the activities at the booth, especially the weighing. In the other Hub, few children attended the Markets. Children aged 10 or above were largely absent. In this second STEM Hub, we had far more success when we set up our booth at a well-known community fair. Youth in this town looked

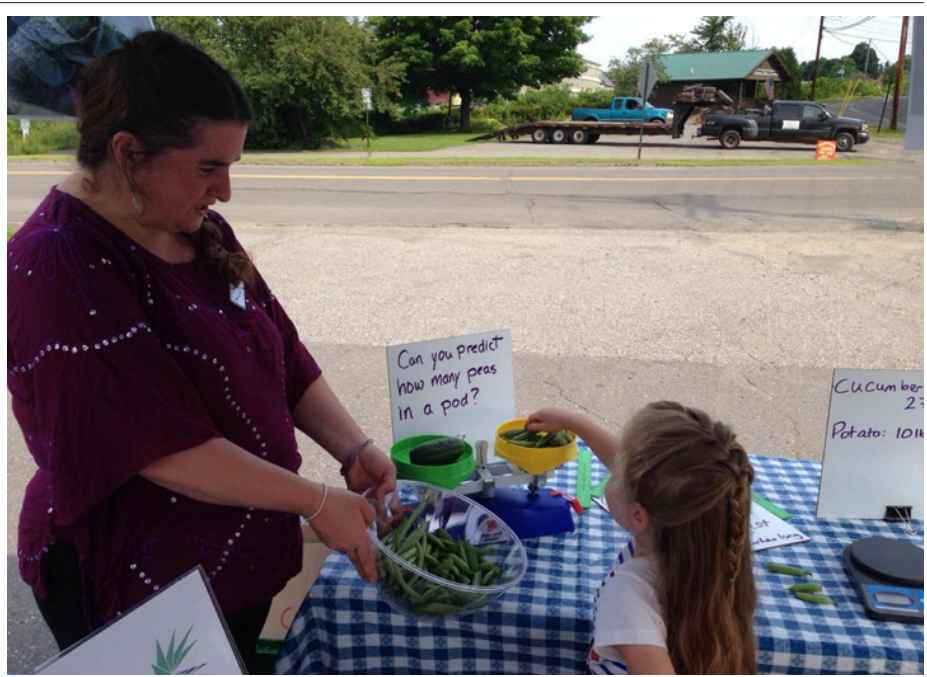

Figure 2. STEM Guide, Becca Myers, encourages a young visitor to the Dover Cove Farmers Market to try using a scale to find out how many ounces her handfuls of string beans weigh.

forward to the fair for weeks in advance, and as a result, we were relatively certain that we would have a willing audience. We found that at the community fair, our math booth had more participants than the surrounding booths, in part because of the large overall turnout and in part because we did not charge a fee for the activities (while other booths charged fees). We decided to offer youth/families a sample of the produce (apples) that they had worked with, a gesture that was appreciated by participants.

Finding additional meaningful place-based venues for families is the key next step for this work. For example, in rural Damariscotta, the Pumpkinfest presents a plethora of mathematical opportunities. The most obvious of these is the pumpkin weighing contest, which involves mathematical comparisons of gargantuan pumpkins that are carefully brought in on flatbed trucks. The winning pumpkin weighed over 1600 pounds in 2014. We anticipate giving each participant at our booth a regular-sized pumpkin (approximately 5-6 pounds), and asking them to compare it with the behemoth. This comparison involves more complexity, including the ideas of percentage and order of magnitude. Does a regular pumpkin weigh about ten percent, one percent, or even less than one percent of the record holder? In addition, more complex tools for measuring weight come into play: How is an object of this size weighed, and how accurate is the weight? Finally, we hope to work with measurements and comparisons of growth time.

\section{DISCUSSION}

The activities that we provided through Farmers Markets and a community fair seemed in many ways a rural analog of exhibits at science centers. That is, the booth drew in a wide variety of people, including our target audience of middle school youth and families. This provided opportunities for 
people to do math together, often in peer or family dyads or small groups. As we saw the range of people who were attracted to the booth, we broadened the mathematical tasks that were involved and gave younger children developmentally appropriate tasks of weighing and using scales. At the same time, we kept our focus on giving older youth opportunities to practice mental math and develop their computational fluency.

1) Where Was the Mathematics? All youth used different kinds of scales that they might not ordinarily use. Of particular interest were the digital scales and pan balances, tools that students have few opportunities to use in their classrooms. Measurement is an area of mathematics where American students perform relatively poorly, for two reasons: First, they have few opportunities at school to actually weigh or measure objects (NCTM, 2003). Second, today's students have fewer opportunities than those of prior generations to practice weighing and measuring at home. In past generations, projects such as cooking, sewing, gardening, and building served to enhance young people's measurement skills (NCTM, 2003.) Thus, an important mathematical feature of the work we did at the Farmers' Markets and fair was the capitalizing on the opportunity to practice measurement skills.

The second important skill set that youth were able to practice when they visited the booth was mental mathematics, which is an important component of "computational fluency" (Russell, 2000). When someone attempts to find out how many of item A it would take to weigh the same as item $\mathrm{B}, \mathrm{s} / \mathrm{he}$ is basically solving a division problem. But it is not a computational problem that announces itself in the sense of "divide __ by __." Part of computational fluency is understanding what is needed in a given mathematical situation to obtain a desired goal and then deciding what strategies to use. In the weighing problem, building up by multiplying is an equally valid strategy as division. (For example, 2 strawberries weigh 0.8 ounces; therefore $2 \times 10$ or 20 strawberries weigh about 8 ounces.) Another aspect of computational fluency is determining when an exact answer versus an approximation is needed. Our task necessarily involved an approximation because there was variability in the weight of the individual pieces of produce. It was up to the participant to figure out "about" how much one piece of produce weighed, and then extrapolate to determine "about" how many of them would weigh as much as the record-holder. This seemingly simple task involved a great deal of computational fluency!

\section{2) The Benefits of Doing Place-Based Math in Rural Set-} tings. When it comes to mathematics, rural communities have significant and unrecognized "Funds of Knowledge" (González et al., 2005). Of course, similar Funds of Knowledge are also inherent in food markets and fairs in urban areas, but we argue that these events are more salient in rural settings. Simply put, fairs and community events are an integrated part of the fabric of rural life. There is a substantial impact of these events on everything from traffic to local economies. There is a social impact as well. Those who participate in rural Farmers Markets are twice as likely as those who attend urban markets to indicate that they value the opportunity to meet and talk with others at the market $(41 \%$ at a rural market vs. $20 \%$ at an urban market; Alonso and O'Neill, 2011). Whether markets are in rural or urban areas, those who attend value the "educational" opportunities of learning more about local produce, farming, and nutrition (Alonso and O'Neill, 2011). Our work suggests that the educational value of these markets might be extended beyond the nutritional aspects.

In rural settings, food-related community events are huge draws. For example, attendance at the Blue Hill Fair (which includes a large Farmers Market) is 29,000, compared to the town's population of 2,400. The Maine Lobster Festival in Rockland draws 30,000-40,000 people, compared to Rockland's population of 7,000. While local organizers have not disaggregated attendance of local residents from that of tourists, it is clear that those living in the areas are highly impacted. Famers Markets and fairs have a presence in rural communities that makes them a potentially compelling context for implementing educational activities - in these cases, those of a mathematical nature.

We argue that place-based math includes important and familiar mathematics that simply takes the form of familiar commercial activities or is a part of community celebrations. The venue we used, while very familiar to most Americans, is not that different from the venue that was examined in a classic study of the mathematical expertise of young street vendors in Brazil (Carraher and Schliemann, 1985). One context is more familiar to us, and the other is more familiar to Brazilians. Both present opportunities for learning mathematics. Two of the original authors of the Brazilian street vendor study have done a deep examination of ways in which the mathematics learned "on the street" is relevant to school mathematics. They conclude that it is indeed relevant, and further that "the outstanding virtue of out of school situations lies not in their realism but rather in meaningfulness" (Carraher and Schleiman, 2002, p. 273). Because our work was a feasibility study, we did not examine what the youth who participated in the Farmers Markets and fairs learned about mathematics. But we learned that these situations presented mathematical problems that were meaningful to rural youth.

Interestingly, the work that we did in Farmers Markets and in a community fair had many benefits that went beyond the mathematics done by young people. The booths provided a direct way to draw in adults and caregivers, and to do mathematics together. It provided adults with opportunities 
to "talk math" with children and with other adults. Furthermore, we made connections with local farmers, who were curious about our work and gave us agricultural and mathematical suggestions about which produce might be most appropriate for the task at hand. We strengthened community connections by buying the farmers' produce to use in our mathematical work. All of the participants were given some of the produce to take home, so we were also helping families sample locally grown foods. Essentially, we were able to draw out the meaningful mathematics in an everyday rural context, to make it more visible to a range of people, and to demonstrate that mathematics is indeed a place-based and community-oriented enterprise.

\section{AUTHOR INFORMATION \\ Corresponding Author}

Jennifer Atkinson, Maine Mathematics and Science Alliance; jatkinson@mmsa.org.

\section{Author Contributions}

The manuscript was written through contributions of all authors. All authors have given approval to the final version of the manuscript. Jan Mokros is currently a Senior Scientist at Science Education Solutions, and can be reached at JanMokros@gmail.com

\section{FUNDING SOURCES}

The research in this paper was supported by NSF grant \#1322827. Any opinions, findings, and conclusions or recommendations expressed in this material are those of the authors and do not necessarily reflect the views of the National Science Foundation.

\section{ACKNOWLEDGMENTS}

The author wishes to thank project staff Veronica Young, Jo Gates, Alyson Saunders, Sue Allen, Lynn Farrin, Judy Matthews, and Becca Meyers for their significant contributions to this work.

\section{ABBREVIATIONS}

CSA: community-supported agriculture; PBME: placebased math education.

\section{REFERENCES}

Alonso, A. D., and O’Neill, M. A. (2011). Investing in the social fabric of rural and urban communities: A comparative study of two Alabama farmers' markets. Community Development, 42(3), 392-409.

Bishop, A. J. (1991). Mathematical Enculturation: A Cultural Perspective on Mathematics Education. Norwell, MA: Kluwer Academic Publishers.

Bishop, J. W., Otto, D. A., and Lubinski, C. A. (2001). Promoting algebraic reasoning using students' thinking. Mathematics Teaching in the Middle School, 6(9), 508-514.

Burns, M., and Sheffield, S. (2004). Math and literature. Sausalito, CA: Math Solutions Publications.

Carraher, D., and Schliemann, A. (2002). Modeling reasoning. In K. Gravemeijer, R. Lehrer, V. Oers and L. Verschaffel (Eds.), Symbolizing, Modeling and Tool Use in Mathematics Education (pp. 295-304). The Netherlands: Kluwer Academic Publishers

Carraher, T. N., and Schliemann, A. D. (1985). Computation routines prescribed by schools: Help or hindrance? Journal for Research in Mathematics Education, 16(1), 37-44.

Civil, M. (2007). Building on community knowledge: An avenue to equity in mathematics education. In N. Nasir amd P. Cobb (Eds.), Improving access to mathematics: Diversity and equity in the classroom (pp. 105-117). New York: Teachers College Press.

Civil, M. (2010). Involving Latino and Latina Parents in Their Children's Mathematics Education Brief National Council of Teachers of Mathematics Research Brief. Reston, VA.

Civil, M., and Andrade, R. (2003). Collaborative Practice with Parents. In A. Peter-Koop, V. Santos-Wagner, C. Breen and A. Begg (Eds.), Collaboration in Teacher Education (Vol. 1, pp. 153-168): Springer Netherlands.

Civil, M., and Bernier, E. (2006). Exploring images of parental participation in mathematics education: Challenges and possibilities. Mathematical Thinking and Learning: An International Journal, 8(3), 309-330.

Coladarci, T. (2007). Improving the yield of rural education research: An editor's swan song. Journal of Research in Rural Education, 22(3).

Damariscotta Pumpkinfest and Regatta. (2015). Retrieved February 18, 2015, from http://damariscottapumpkinfest.com/

Design Zone. (2018). Retrieved September 17, 2018, from http:// www.omsi.edu/products/design-zone/

Gailey, S. K. (1993). The Mathematics--Children's-Literature Connection. Arithmetic Teacher, 40(5), 258-261.

Goldenberg, P., and Shteingold, N. (2007). Early Algebra: The MW Perspective. In A. Blanton and J. Kaput (Eds.), Algebra in the Early Grades. Hillsdale, NJ: Erlbaum.

González, N., Moll, L., and Amanti, C. (2005). Funds of knowledge: Theorizing practices in households, communities and classrooms. Mahwah, NJ: Erlbaum.

Guinness Book of World Records. (2015). Retrieved February 21, 2015, from http://www.guinnessworldrecords.com/ 
Gutstein, E. (2006). Reading and writing the world with mathematics: toward a pedagogy for social justice (Critical social thought). New York: Routledge.

Howtosmile. (2018). Retrieved September 17, 2018, from http:// www.howtosmile.org/

Howley, A., Howley, M., Camper, C., and Perko, H. (2011). Placebased education at Island community school. Journal of Environmental Education, 42(4), 216-236.

Howley, A., Pendarvis, E., and Gholson, M. (2005). How talented students in a rural school district experience school mathematics. Journal for the Education of the Gifted, 29(2), 123-160.

Howley, C. B., Showalter, D., Klein, R., Sturgill, D. J., and Smith, M. A. (2013). Rural math talent, now and then. Roeper Review, 35(2), 102-114.

Gilon, P. (2017). Navajo Math Circles. Tribal College Journal of American Indian Higher Education, 28(4). Retrieved September 13, 2018, from https://tribalcollegejournal.org/navajo-math-circles/

Kamila, A. (2012, September 27). They might be giants, Portland Press Herald. Retrieved from http://www.pressherald. com/2012/09/27/they-might-be-giants_2012-09-27/

Kannapel, P. J., Aagaard, L., Coe, P., and Reeves, C. A. (2000). Implementation of the Kentucky nongraded primary program. Education Policy Analysis Archives, 8.

Kannapel, P. J., Aagaard, L., Coe, P., Reeves, C. A., and Ael, I. C. W. V. (2000). Elementary Change: Moving toward Systemic School Reform in Rural Kentucky. Washington D.C.: United States Department of Education.

Kliman, M. (2006). Math out of school: Families' math game playing at home. School Community Journal, 16(2), 69-90.

Maine Association of Agricultural Fairs. (2018). About MAAF. Retrieved September 17, 2018, from http://www.mainefairs.org/about.html

Maine Mathematics and Science Alliance. (2018). STEM Guides: Connecting Rural Youth to Informal STEM. 2018 STEM for All Video Showcase. Retrieved September 19, 2018 from http://stemforall2018.videohall.com/presentations/1189

Maine Organic Farmers and Gardeners Association. (2018). September 17, 2018, from http://www.mofga.org/

Math Olympiads. (2018). Retrieved September 17, 2018, from http://www.moems.org

MathAlive Exhibit. (2018). Retrieved September 17, 2018, from http://mathalive.com/about-the-exhibit/

MathCounts Foundation. (2018). Retrieved September 17, 2018, from http://mathcounts.org

MathCounts Foundation. (2018). The National Math Club. Retrieved September 17, 2018, from https://www.mathcounts.org/programs/math-club

Mathematical Association of America. (2018). American Mathematics Competitions. Retrieved September 17, 2018, from http://www.maa.org/math-competitions

MathMoves! (2018). Exhibits. Retrieved September 17, 2018 from http://www.mathmoves.org/exhibits.html
Mokros, J. (1996). Beyond Facts and Flashcards: Exploring Math with Your Kids. Portsmouth, New Hampshire: Heinemann.

Nasir, N. i. S., and Paul., C. (2007). Improving access to mathematics: diversity and equity in the classroom. Multicultural education series; Variation: Multicultural education series (New York, N.Y.): Teachers College Press.

National Association of Math Circles. (2018). Retrieved September 17, 2018, from www.mathcircles.org

National Center for Education Statistics. (2013). The Status of Rural Education. Figure 7: Averaged freshman graduation rate (AFGR) for public high school students, by locale: School year 2008-09. Retrieved September 13, 2018 from https://nces.ed.gov/programs/coe/indicator_tla.asp

National Council of Teachers of Mathematics (NCTM). (2003). Learning and Teaching Measurement 65th Yearbook. (D. Clements Ed.). Reston, Virginia: National Council of Teachers of Mathematics.

National Student Research Clearinghouse. (2016). High School Benchmarks 2016. Figure A: College Enrollment Rates in the First Fall after High School Graduation, Class of 2015, Public Non-Charter Schools. Retrieved September 13, 2018 from https://nscresearchcenter.org/hsbenchmarks2016/

Porter, M. K. (1995). The Bauer County Fair: Community celebration as context for youth experiences of learning and belonging. Journal of Research in Rural Education, 11(3), 139-156.

Russell, S. J. (2000). Developing computational fluency with whole numbers in the elementary grades. New England Mathematics Journal, 32(2), 40-54.

Showalter, D. A. (2013). Place-based mathematics education: A conflated pedagogy? Journal of Research in Rural Education, 28(6), 1-13. Retrieved from http://jrre.psu.edu/articles/28-6. pdf

State of Maine Department of Agriculture, Conservation and Forestry Pumpkin Cam. (2015). Retrieved February 18, 2015, from http://www.maine.gov/dacf/pumpkincam/

STEM Resource Bank. (2018). Retrieved September 17, 2018, from https://mmsa.org/stem-resource-bank/

Thompson, V. H. M.-I. K. (1998). Family math, the middle school years: algebraic reasoning and number sense. Berkeley, CA: Lawrence Hall of Science, University of California.

Tiedemann, K., and Brandt, B. (2010). Parents' Support in Mathematical Discourses. In U. Gellert, E. Jablonka \& C. Morgan (Eds.), Proceedings of the 6th International Conference on Mathematics Education and Society (pp. 428-437). Berlin: Freie Universitat Berlin.

Tieken, M. C. (2014). Why rural schools matter. Chapel Hill: University of North Carolina Press.

United States Census Bureau. (2016). New Census Data Shows Difference Between Urban and Rural Populations. Retrieved September 13, 2018 from https://www.census.gov/ newsroom/press-releases/2016/cb16-210.html

United States Department of Education 21st Century Community Learning Centers. (2015). Retrieved February 18, 2015, from http://www2.ed.gov/programs/21stcclc/index.html 
Van Voorhis, F., Maier, M., Epstein, J., and Lloyd, C. (2013). The Impact of Family Involvement on the Education of Children Ages 3 to 8.

Vital Signs. (2012). Lost Opportunity: Few U.S. Students Participate in STEM Out-of-School Programs. Washington DC. Retrieved February 18, 2015 from https://www.ecs.org/ initiatives/stem-vital-signs/

White, J., Barrett, K., Kopp, J., Manoux, C., Johnson, K., and McCullough, Y. (2006). Math in the Garden: Hands-On Activities That Bring Math to Life. Ages 5-13. Williston, Vermont: National Gardening Association 